\title{
Produção de mudas das leguminosas leucena, gliricídia e moringa em Redenção, Ceará
}

\author{
Febriana Correia Ximenes Carvalho', Maria Gorete Flores Salles²*, Ciro de Miranda Pinto², Olienaide \\ Ribeiro de Oliveira Pinto ${ }^{2}$, Aderson Martins Viana Neto ${ }^{3}$, Inti Campos Salles Rodrigues ${ }^{4}$
}

\begin{abstract}
RESUMO: O objetivo foi produzir mudas de leguminosas em diferentes substratos e períodos do ano. Utilizaram-se três substratos (solo, solo + esterco bovino e solo + bagana de carnaúba) para as mudas de leucena por sementes e estacas $(30$ e $40 \mathrm{~cm})$, gliricídia por estacas $(40 \mathrm{~cm})$ e de moringa por sementes em duas profundidades $(1,5 \mathrm{e} 3 \mathrm{~cm})$. Usou-se um delineamento inteiramente casualizado em arranjo fatorial e cada repetição foi composta por quatros sacos. No período chuvoso, o IVE das sementes de leucena foi melhor nos substratos solo + esterco e solo; na altura de planta e número de folhas no substrato solo + bagana. Nas sementes de moringa, o IVE foi semelhante nos três substratos na profundidade de $3 \mathrm{~cm}$. No período seco, a estaca de $40 \mathrm{~cm}$ da leucena teve maior número de brotações no substrato solo + esterco e de folhas no substrato solo + bagana. Na estaca de gliricídia o número de brotações e folhas foi melhor no substrato solo + bagana. Produzir mudas de leucena e moringa por sementes é viável em substratos adicionados de matéria orgânica animal e vegetal, na profundidade de $3 \mathrm{~cm}$ e, por estacas de $40 \mathrm{~cm}$ de leucena e gliricídia.
\end{abstract}

Palavras-chave: Leucaena leucocephala, Gliricidia sepium, Moringa oleifera

\section{Production of the leguminous seedlings of leucaena, gliricidia and moringa in the Ceará}

\begin{abstract}
The objective was to produce legume seedlings in different substrates and periods of the year. Three substrates (soil, soil + bovine manure and soil + carnauba bagana) were used for leucaena seedlings and cuttings (30 and $40 \mathrm{~cm})$ gliricidia by cuttings $(40 \mathrm{~cm})$ and moringa by seeds at two depths $(1.5$ and $3 \mathrm{~cm})$. A completely randomized design in factorial arrangement for leucaena, moringa and gliricidia was used, in each replicate it was composed of four bags. In the rainy season, the IVE of the leucaena seeds was better in soil substrates + manure and soil and plant height and number of leaves in the substrate soil + bagana. In the moringa seeds, IVE was similar in the three substrates at depth of $3 \mathrm{~cm}$. In the dry period, the $40 \mathrm{~cm}$ stem of the leucaena had a higher number of shoots, in the substrate soil + manure and the largest number of leaves in the soil substrate + bagana. In the gliricidia stakes the number of sprouts and leaves was better in the substrate soil + bagana. The production of leucaena and moringa seedlings by seeds is viable in substrates added with plant and animal organic matter, at depth of $3 \mathrm{~cm}$, and by stakes of $40 \mathrm{~cm}$ of leucaena and gliricidia.
\end{abstract}

Keywords: Leucaena leucocephala, Gliricidia sepium, Moringa oleifera

\section{INTRODUÇÃO}

A alimentação animal é uma proporção significativa dos custos de produção para o produtor pecuário, especialmente $\mathrm{o}$ pequeno agricultor familiar. Neste raciocínio, é importante utilizar fontes alimentares alternativas objetivando melhorar a relação custo/benefício das dietas, assim, o uso de leguminosas tropicais, com a finalidade de suprir as necessidades proteicas dos animais, é uma alternativa viável, tanto do ponto de vista nutricional quanto econômico (CÂMARA et al., 2015).

$\mathrm{O}$ uso de leguminosas como bancos de proteínas ou em consórcio com gramíneas, tem se mostrado viável, pelo alto valor alimentício e excelente aceitabilidade pelos animais, além da habilidade para crescer em solos de baixa fertilidade, rápida dispersão e ciclo longo, fazem com que leguminosas sejam utilizadas na alimentação de ruminantes e não ruminantes (EVANGELISTA; LIMA, 2013). Vale ressaltar que as leguminosas para formar os bancos de proteínas devem ser, adaptadas às condições edafoclimáticas locais, tolerantes à seca, apresentarem elevado teor principalmente, serem consumidas pelos animais.

A leucena (Leucaena leucocephala (Lam.) De Wit.) faz parte das espécies forrageiras promissoras e muito utilizadas no semiárido brasileiro, pela boa aceitação pelos ruminantes (SILVA et al., 2015) e monogástricos (ARRUDA et al. 2010) sendo uma fonte proteica de alta qualidade nutricional e excelente fonte de macro e micronutrientes (BAYÃO et al., 2016). O material foliar da leucena é uma excelente fonte de $\beta$-caroteno, precursor da

\footnotetext{
Recebido em 31/07/2018; Aceito para publicação em 01/11/2019

${ }^{1}$ Universidade Nacional Timor Lorosa'e

2 Universidade da Integração Internacional da Lusofonia Afro-Brasileira

${ }^{3}$ Universidade Federal do Ceará

4 Universidade Estadual do Ceará

*E-mail: gorete@unilab.edu.br
} 
vitamina $A$, com vital importância na época seca, quando o pasto geralmente está seco e a leucena apresenta-se verde (EVANGELISTA; LIMA, 2013). Salienta-se ainda, a capacidade de rebrota, mesmo nos períodos de seca (CÂMARA et al., 2015). Na aquicultura, o feno de leucena pode substituir o farelo de soja em até $40 \%$ para a produção de alevinos de tilápia (SEGUNDO et al., 2006; ARAUJO et al., 2012). Na avicultura, a inclusão de $20 \%$ do feno de leucena em dietas para aves caipiras foi eficaz nas fases de cria e recria (ARRUDA et al., 2010). E em poedeiras a inclusão de $2 \%$ de feno de folha de leucena elevou a pigmentação das gemas (LOPES et al., 2014).

A gliricídia (Gliricidia sepium) é uma espécie com valores de proteína bruta elevados, sendo adequada para alimentação de ruminantes (ANDRADE et al., 2015), na forma de feno ou silagem. É usada na suplementação alimentar em época seca ou chuvosa pelo seu teor mais elevado de proteína do que as gramíneas (SANTANA NETO et al., 2015). Possui a capacidade de adaptação em regiões com baixa precipitação pluviométrica, devido ao sistema radicular profundo que propicia a reciclagem dos nutrientes do subsolo, como também, a absorção de água das camadas profundas, bem como pela boa capacidade de produzir biomassa em condições de baixa disponibilidade hídrica (MARIN et al., 2007).

As folhas da moringa (Moringa oleifera se constituem em uma boa fonte proteica com $33,8 \%$ de proteína bruta e digestibilidade média de 79,7\%, o que a configura como um bom suplemento para animais (SÁNCHEZ et al., 2006; MARINHO et al., 2016), além de sua composição em vitaminas A, B e $\mathrm{C}$ e em minerais como, ferro, cálcio, fósforo, potássio e zinco (MOYO et al., 2013). Oliveira et al. (2017) utilizaram o feno de moringa na alimentação de bezerros lactentes da raça Pantaneira, com resultados positivos. Em aves, Cadeau (2017) concluiu que as sementes de moringa são um ingrediente que pode ser utilizado na alimentação seja como nutriente ou energia, ou como aditivo alimentar. Em frangos de corte, Nkukwana et al. (2015) utilizaram farinha das folhas de moringa na alimentação com ganho de peso, sendo uma alternativa para baratear custos. Em coelhos, a inclusão de folhas da moringa em $20 \%$ da dieta aumentou o ganho de peso diário (UFELE et al., 2013). Por outro lado, a moringa também possui potencial como planta apícola (KIILL et al., 2012).

Assim, o uso dessas espécies é importante para a alimentação dos animais de produção criados em regiões tropicais, principalmente por pequenos agricultores familiares. Desta forma, o presente trabalho objetivou avaliar a produção de mudas de leucena, gliricídia e moringa em diferentes substratos e períodos do ano em Redenção, no Ceará.

\section{MATERIAL E MÉTODOS}

O experimento foi conduzido na Fazenda Experimental Piroás, da Universidade da Integração Internacional da Lusofonia Afro-Brasileira (UNILAB), localizada no município de RedençãoCeará, situado à latitude de $4^{\circ} 33^{\prime} 35^{\prime}$ ' $\mathrm{S}$, longitude $38^{\circ} 43^{\prime} 50^{\prime}$ ' $\mathrm{O}$ e altitude de $88,8 \mathrm{~m}$; temperatura média anual ente $26^{\circ} \mathrm{C}$ a $28^{\circ} \mathrm{C}$, precipitação pluviométrica de $1.060,0 \mathrm{~mm}$, sendo o clima da região caracterizado como quente úmido (IPECE, 2017).

Os trabalhos ocorreram durante três meses no período chuvoso (março, abril e maio) e três meses no seco (setembro, outubro e novembro) de 2017.

Para produzir as mudas de leguminosas foram utilizadas as culturas da família Fabaceae e Moringaceae como estacas e semente de leucena, estacas de gliricídia e sementes de moringa em diferentes substratos (solo, solo + esterco bovino e solo + bagana de carnaúba).

Com um carrinho de mão, foram trazidos e medidos os componentes que formaram os substratos e, feita a proporção onde, para o substrato solo foram adicionados 2 carinhos de mão de arisco +2 carinhos de mão de areia (2:2). Para o substrato solo + esterco bovino foram adicionados 1 carinho de mão de arisco +1 carinho de mão de areia +1 carinho de mão de esterco bovino $(1: 1: 1)$ e, para o substrato solo + bagana de carnaúba foram adicionados 1 carinho de mão de arisco +1 carinho de mão de areia +1 carinho de mão de bagana de carnaúba $(1: 1: 1)$.

Todas as mudas das três leguminosas (leucena, gliricídia e moringa) foram produzidas em sacos plásticos com dimensão de 11 x $23 \mathrm{~cm}$ para a propagação de mudas por sementes e com as dimensões de $25 \times 25 \mathrm{~cm}$ para propagar as mudas por estacas.

No início da produção de mudas foram coletados os dados climáticos de temperatura ambiente (TA) e umidade relativa do ar (UR) por um termohigrômetro digital (INCOTERM), onde foram anotados os valores médios, máximos e mínimos das variáveis climáticas, para o posterior cálculo dos valores médios, máximos e mínimos do ITU (Índice de Temperatura e Umidade) a partir do modelo de Thom, (1959): ITU = 0,8 x T + (UR (\%) /100) x [(T $-14,4)+46,4]$, onde T: Temperatura ambiente $\left({ }^{\circ} \mathrm{C}\right)$ e UR: Umidade relativa do ar $(\%)$ e verificar o conforto térmico ambiental.

As sementes de leucena foram coletadas de árvores matrizes, situadas no Campus da Liberdade da UNILAB, em Redenção-CE e após selecionadas. Para a quebra da dormência das sementes, estas foram imersas em água à temperatura ambiente, durante 12 horas. A semeadura foi realizada com 
duas sementes em cada saco plástico a uma profundidade de $2,0 \mathrm{~cm}$, e nas 4 semanas de plantio foram realizados desbastes, deixando somente uma plântula para completar seu ciclo.

As estacas de leucena foram obtidas de árvores matrizes da fazenda experimental da UNILAB, na localidade de Piroás. Com uma fita métrica foram mensurados dois tamanhos de estacas $(30 \mathrm{~cm}$ e 40 $\mathrm{cm})$, para tanto foram observados e anotados o número de gemas, aferidos o diâmetro com auxílio de um paquímetro digital e obtido o peso de cada estaca por uma balança digital. Para as estacas de leucena o número de médio de gemas foi de 10,92; peso médio de $75,36 \mathrm{~g}$ e o diâmetro médio de 2,45 $\mathrm{cm}$. Todos estes parâmetros foram adquiridos antes do plantio em saco plástico, onde $2 / 3$ de cada estaca foi introduzido nos diferentes substratos. Estas mudas foram irrigadas diariamente, às $7 \mathrm{~h}$ da manhã.

As mudas de gliricídia foram obtidas por estacas. Com uma fita métrica mediu-se as estacas de $40 \mathrm{~cm}$ da gliricídia obtidas de árvores matrizes da fazenda experimental da UNILAB, na localidade de Piroás. Foram observados os números de gemas $\mathrm{e}$ mensurados o diâmetro com o paquímetro digital e o peso com a balança digital. A gliricídia teve número de médio de gemas de 10,80; o peso médio de $111,32 \mathrm{~g}$ e o diâmetro médio de $1,79 \mathrm{~cm}$.

As mudas de moringa foram obtidas por sementes oriundas de uma única árvore matriz do município litorâneo de Icaraí de Amontada, Ceará, com auxílio de dois gabaritos que foram medidos e marcados com $1,5 \mathrm{~cm}$ e $3,0 \mathrm{~cm}$ para as duas profundidades, que foram semeadas $(1,5 \mathrm{~cm}$ e 3,0 $\mathrm{cm}$ ) nos três tipos de substratos (solo, solo + esterco bovino e solo + bagana), nos sacos plásticos.

Para as mudas de leucena o número de folhas e altura das plantas em estacas, empregou-se o delineamento inteiramente casualizado num arranjo fatorial 3x2x8 (três substratos; dois tamanhos de estaca 30 e $40 \mathrm{~cm}$ de comprimento; épocas de avaliação aos 7, 14, 21,28, 35, 42, 49 e 56 dias) com 10 repetições.

Para avaliar o índice de velocidade de emergência (IVE) das sementes de leucena utilizou- se o delineamento inteiramente casualizado num arranjo fatorial 3x6 (três substratos; épocas de avaliação aos $4,7,10,13,16,19,22,25,28,31,34$ e 37 dias) com 10 repetições. A altura e número de folhas das mudas de leucena por semente, usou-se o delineamento inteiramente casualizado num arranjo fatorial 3x2 (três substratos; épocas de avaliação dias) com 10 repetições.

Para número de folhas, número de brotações das estacas de gliricídia utilizou-se o delineamento inteiramente casualizado num arranjo fatorial $3 \times 8$ (três substratos; épocas de avaliação aos 7, 14, 21,28, 35, 42, 49 e 56 dias) com 10 repetições.

Para o índice de velocidade de emergência (IVE) das sementes de moringa utilizou-se o delineamento inteiramente casualizado num arranjo fatorial $3 \times 2 \times 6$ (três substratos; duas profundidades de plantio das sementes; épocas de avaliação aos $4,7,10,13,16$, 19 dias) com 10 repetições. O número de folhas e altura de plantas utilizou-se o delineamento inteiramente casualizado num arranjo fatorial $3 \times 2 \times 3$ (três substratos; duas profundidades de plantio das sementes; duas épocas de avaliação) com 10 repetições. Para diâmetro de caule, utilizou-se o delineamento inteiramente casualizado num arranjo fatorial $3 \times 2 \times 2$ (três substratos; duas profundidades de plantio das sementes; duas épocas de avaliação) com 10 repetições.

Os dados foram submetidos à análise de variância e, significância pelo teste $\mathrm{F}$ a $5 \%$ de probabilidade, as médias dos tratamentos qualitativos foram comparadas pelo teste de Tukey ao nível de 5\% de probabilidade. Para dados quantitativos empregou-se a análise de regressão polinomial. Para tanto, utilizou-se o ASSISTAT 7,7 beta, sistema de análise estatística da UFCG (SILVA; AZEVEDO, 2016).

\section{RESULTADOS E DISCUSSÃO}

Os parâmetros climáticos (Tabela 1), do período chuvoso para a produção de mudas por sementes, da leucena e moringa mostram que os valores médios, máximos e mínimos de $26,3^{\circ} \mathrm{C}, 28,4^{\circ} \mathrm{C}$ e $24,1^{\circ} \mathrm{C}$, respectivamente, da temperatura ambiente, foram ideais para a emergência das sementes.

Tabela 1. Médias, máximas e mínimas de temperatura ambiente, umidade relativa do ar e índice de temperatura e umidade do período chuvoso, na produção de mudas por sementes de leucena e moringa.

\begin{tabular}{lllll}
\hline Período & Valores & TA $\left({ }^{\circ} \mathrm{C}\right)$ & UR $(\%)$ & ITU \\
\hline Chuvoso & Médias & 26,3 & 87 & 77,8 \\
& Máximas & 28,4 & 89 & 81,6 \\
\multirow{2}{*}{ Seco } & Mínimas & 24,1 & 75 & 72,9 \\
& Médias & 27,3 & 64 & 76,5 \\
& Máximas & 29,5 & 73 & 81,0 \\
& Mínimas & 26,6 & 51 & 73,9 \\
\hline
\end{tabular}

TA: temperatura ambiente, UR: umidade relativa do ar e ITU: índice de temperatura e umidade

A produção de mudas da leucena (Leucaena leucocephala) por semente no período chuvoso do ano 2017, apresentou melhores resultados para o índice de velocidade de emergência (IVE) quando 
foram utilizados os substratos solo + esterco bovino e solo, com exceção do substrato solo + bagana de carnaúba (Tabela 2). O substrato solo + esterco bovino possui um elevado nível de matéria orgânica, rápida disponibilidade de nitrogênio à planta, e maior teor de potássio e fósforo, o que preencheu os requisitos nutritivos para a emergência das sementes.

As variáveis altura de planta e número de folhas (Tabela 2) das mudas de leucena por semente apresentaram um melhor desenvolvimento no substrato solo + bagana de carnaúba, enquanto que o substrato solo proporcionou menor desenvolvimento dessas variáveis. Em virtude do substrato solo + bagana de carnaúba possuir uma elevada relação carbono/nitrogênio $(\mathrm{C} / \mathrm{N})$, provavelmente o período de compostagem não tenha suficiente para decompor esse material e disponibilizar nutrientes para um bom desenvolvimento das plântulas. Esse fato foi contrário ao que ocorreu com os substratos formulados com o composto solo + esterco de bovino e o solo. Para Korndorfer (2003), a adubação do solo com substratos contendo uma relação $\mathrm{C} / \mathrm{N}$ elevada, no exemplo a bagana de carnaúba, motiva a competição pelo $\mathrm{N}$ disponível entre os microrganismos e as plantas. Resíduos com relação $\mathrm{C} / \mathrm{N}$ baixas, como as leguminosas, podem favorecer o desenvolvimento microbiológico no processo de decomposição, implicando em maior quantidade de $\mathrm{N}$ mineralizado. As variáveis altura de planta e número de folhas expressaram maior desenvolvimento no substrato solo + bagana de carnaúba aos 37 dias após plantio, em relação demais tratamentos (Tabela 2). O que pode denotar o efeito positivo da bagana de carnaúba na retenção de água e manutenção da umidade no substrato, proporcionando o maior desenvolvimento das plantas de leucena. Resultados semelhantes foram encontrados por Oliveira et al. (2009), no experimento com Copernicia hospita Martius em função do substrato com bagana de carnaúba e composto orgânico. Também Araújo et al. (2017) obtiveram os melhores resultados para altura de planta, produção de massa seca da parte aérea e total e o número de folhas nas mudas de paricá (Schizolobium amazonicum) produzidas no substrato bagana de carnaúba.

Tabela 2. Índice de velocidade da emergência (IVE), altura da planta, e número de folhas em mudas por sementes de leucena.

\begin{tabular}{|c|c|c|}
\hline Substrato & IVE & \\
\hline $\begin{array}{l}\text { Solo + E* } \\
\text { Solo + B } \\
\text { Solo } \\
\end{array}$ & $\begin{array}{l}1,8625 \mathrm{a} \\
1,7917 \mathrm{~b} \\
1,8083 \mathrm{a} \\
\end{array}$ & \\
\hline \multirow{2}{*}{ Substrato } & Altura de planta $(\mathrm{cm})$ & \\
\hline & 28 dias DAP $* * *$ & 37 dias DAP*** \\
\hline Solo + E* & $6,0433 \mathrm{aB}$ & $15,0750 \mathrm{bA}$ \\
\hline Solo + B & $4,3470 \mathrm{aB}$ & $20,2250 \mathrm{aA}$ \\
\hline Solo & $5,2528 \mathrm{aB}$ & $11,4250 \mathrm{bA}$ \\
\hline \multirow{2}{*}{ Substrato } & Número de folhas & \\
\hline & 28 dias DAP $* * *$ & 37 dias $\mathrm{DAP} * * *$ \\
\hline Solo + E* & $4,8750 \mathrm{abB} * *$ & $6,4500 \mathrm{bA}$ \\
\hline Solo + B & $4,1500 \mathrm{bB}$ & $8,1750 \mathrm{aA}$ \\
\hline Solo & $5,8250 \mathrm{aA}$ & $3,8500 \mathrm{cB}$ \\
\hline
\end{tabular}

*E: esterco bovino; B: bagana de carnaúba

**As médias seguidas pela mesma letra não diferem estatisticamente entre si na coluna com a letra minúscula e na linha letra maiúscula, pelo Teste de Tukey ao nível de $5 \%$ de probabilidade.

*** DAP: dias após o plantio

De acordo com o desdobramento da interação de substrato $\mathrm{x}$ tamanho de estaca de leucena, no número de brotações, verifica-se que os melhores resultados foram obtidos quando se testou o substrato solo + bagana de carnaúba com estaca de $40 \mathrm{~cm}$ e no substrato solo com estaca de $30 \mathrm{~cm}$. Para o número de folhas, os melhores tratamentos foram solo + bagana de carnaúba e solo combinado aos tamanhos de estaca 30 e $40 \mathrm{~cm}$ em detrimento solo + esterco bovino nos tamanhos 30 e $40 \mathrm{~cm}$. Na propagação das mudas de leucena por estacas considerando as variáveis, número de brotações e folhas, recomendase o uso do substrato solo + bagana de carnaúba com estacas de $40 \mathrm{~cm}$ de comprimento. Segundo Korndorfer (2003), os adubos de origem animal, principalmente o esterco bovino, são bons fornecedores de nutrientes, tendo o fósforo $(\mathrm{P})$ e o potássio $(\mathrm{K})$ rapidamente disponível e o nitrogênio (N) ficando na dependência da facilidade de degradação dos compostos.

Os autores, Setúbal e Neto (2000), trabalhando com vários substratos orgânicos, sugerem que os substratos com elevada relação carbono/nitrogênio $(\mathrm{C} / \mathrm{N})$ podem contribuir para a redução da disponibilidade de $\mathrm{N}$ para as mudas. 
Tabela 3. Número de brotações e de folhas nas estacas de 30 e $40 \mathrm{~cm}$ da leucena nos diferentes substratos.

\begin{tabular}{llc}
\hline & \multicolumn{2}{c}{ Número de Brotações } \\
\cline { 2 - 3 } Substratos & \multicolumn{2}{c}{ Tamanho de Estaca } \\
\cline { 2 - 3 } Solo $+\mathrm{E}^{*}$ & $0,7235 \mathrm{bA}^{* * *}$ & $40 \mathrm{~cm}$ \\
Solo $+\mathrm{B}$ & $0,9617 \mathrm{aB}$ & $0,7071 \mathrm{cA}$ \\
Solo & $1,0068 \mathrm{aA}$ & $1,2582 \mathrm{aA}$ \\
& & $1,0338 \mathrm{bA}$ \\
Substratos & $30 \mathrm{~cm}$ & Número de Folhas \\
\cline { 2 - 3 } & $0,7071 \mathrm{bA}$ & Tamanho de Estaca \\
\hline Solo $+\mathrm{E}$ & $1,0484 \mathrm{aA}$ & $0,7071 \mathrm{bA}$ \\
Solo $+\mathrm{B}$ & $0,9799 \mathrm{aA}$ & $1,0582 \mathrm{aA}$ \\
Solo & & $1,0341 \mathrm{aA}$ \\
\hline
\end{tabular}

E: esterco bovino; B: bagana de carnaúba

${ }^{*}$ As médias seguidas pela mesma letra não diferem estatisticamente entre si na coluna com a letra minúscula e na linha letra maiúscula, pelo Teste de Tukey ao nível de $5 \%$ de probabilidade.

$\mathrm{Na}$ tabela 4 constam as equações polinomiais lineares do número de brotações e folhas da leucena. A regressão polinomial linear para números de brotações e folhas em função do período de avaliação em dias apresentaram um coeficiente de determinação, respectivamente de $62,88 \%$ e $74,01 \%$. Os números de brotações nas estacas de leucena apresentaram um comportamento decrescente, reduzindo 0,002 em função dos dias de avaliação. O número de folhas aumentou com o avançar do período de avaliação em 0,004 unidades de tempo em dias. $\mathrm{O}$ número de brotações das estacas de leucena senesceram, isto é, as brotações não se diferenciaram para formação de folhas novas (Tabela 4).

A estaquia é considerada uma das metodologias mais importantes para a propagação de espécies que podem ser propagadas por estacas, esse método apresenta numerosas vantagens, como economia, rapidez e simplicidade (PEREIRA JÚNIOR et al., 2008). Para Marchese et al. (2010), os carboidratos de reserva servem como fonte de energia e produção de carbônicos necessários para a produção de novos tecidos. Isso significa que sem um nível mínimo de carboidratos, o crescimento e desenvolvimento irão cessar. Portanto, baixa quantidade de reservas de carboidratos, não fornecerá a energia necessária para que ocorra um bom enraizamento das estacas (MAYER et al., 2006).

Outro aspecto observado nas estacas de leucena foi que em apenas uma semana já haviam sido emitidos brotos e, dentro de duas semanas, $80 \%$ das estacas já tinham brotado, isto é, o índice de pegamento (IP) das estacas da leucena é muito rápido.

Tabela 4. Equações polinomiais do número de brotações e número de folhas de estacas de leucena.

\begin{tabular}{lll}
\hline Número de brotações & $Y=1,024-0,002 x$ & $R^{2}=62,88 \%$ \\
Número de folhas & $Y=0,768+0,004 x$ & $R^{2}=74,01 \%$ \\
\hline
\end{tabular}

Para o número de brotações da gliricídia, o substrato solo + bagana de carnaúba foi $8,15 \%$ superior ao solo + esterco bovino,enquanto que para a variável número de folhas da gliricídia, o substrato solo foi diferente estatisticamente dos substratos solo + esterco bovino e solo + bagana de carnaúba (Tabela 5). Neste estudo, o comportamento das estacas de gliricídia foi melhor nos substratos adicionados de matéria orgânica, concordando com os resultados de Cavalcante et al. (2016) onde concluíram que a adição de insumos orgânicos proporcionou incremento no crescimento inicial e acumulo de fitomassa seca em mudas de gliricídia.

Tabela 5. Médias do número de brotações e folhas da gliricídia
Pereira Júnior et al. (2008), quando utilizaram estacas de G. sepium, com $30 \mathrm{~cm}$ de comprimento e um diâmetro médio de $4,5 \mathrm{~cm}$, em substrato terra com esterco curtido na proporção de $4: 1$, obtiveram cerca de $7 \%$ de pegamento aos 60 dias após o plantio das estacas. O número de brotações e o número de folhas, apresentaram resposta significativa ao nível de $1 \%$ pelo Teste $\mathrm{F}$, sugerindo que existe diferença entre pelo menos uma das médias dos tratamentos na produção de mudas da gliricídia por estacas (Tabela 5).

\begin{tabular}{lll}
\hline Substratos & Número de brotações & Número de folhas \\
\hline Solo $+\mathrm{E}$ & $1,09284 \mathrm{~b}^{*}$ & $0,72354 \mathrm{~b}$ \\
Solo $+\mathrm{B}$ & $1,25824 \mathrm{a}$ & $0,70711 \mathrm{~b}$ \\
Solo & $1,18193 \mathrm{ab}$ & $0,96175 \mathrm{a}$ \\
\hline
\end{tabular}


$\mathrm{Na}$ tabela 6 constam as equações polinomiais lineares e quadráticas do número de brotações e folhas da gliricídia. Para interpretação de equações polinomiais, considera-se a maior grau. A regressão polinomial quadrática para número de brotações e folhas em função do período de avaliação em dias teve um coeficiente de determinação, respectivamente de $71,58 \%$ e $92,35 \%$, ambas as equações apresentaram ponto de mínima.

Tabela 6. Regressão polinomial linear e quadrática do número de brotações e folhas da gliricídia

\begin{tabular}{llll}
\hline Número de brotações & & & \\
\hline \multirow{2}{*}{ Regressão } & Linear & Quadrática & \\
\cline { 2 - 4 } & $\mathrm{Y}=1,233-0,139 \mathrm{x}$ & $\mathrm{Y}=1,233-0,139 \mathrm{x}+0,011 \mathrm{x}^{2}$ & $\mathrm{R}^{2}=71,58 \%$ \\
\hline Número de folhas & & & \\
\hline \multirow{2}{*}{ Regressão } & Linear & Quadrática & \\
\cline { 2 - 4 } & $\mathrm{Y}=1,045-0,015 \mathrm{x}$ & $\mathrm{Y}=1,045-0,015 \mathrm{x}+0,0001 \mathrm{x}^{2}$ & $\mathrm{R}^{2}=92,35 \%$ \\
\hline
\end{tabular}

Na tabela 7 observa-se que na profundidade de 3 $\mathrm{cm}$ de semeadura das sementes de moringa, o índice de velocidade emergência (IVE) obteve uma resposta semelhante nos substratos solo + esterco bovino, solo + bagana de carnaúba e solo. Enquanto que, na profundidade de $1,5 \mathrm{~cm}$ o IVE teve melhor resultado no substrato solo + esterco bovino e o menor IVE foi obtido no substrato solo. A regressão polinomial quadrática para IVE em função dos dias de avaliação teve um ajustamento de $99,97 \%$ ao modelo matemático. $\mathrm{O}$ período de avaliação ótimo foi 4,23 dias, resultando em um IVE 0,46.

As variáveis altura de planta, número de folhas e diâmetro do caule da planta, apresentaram melhor desenvolvimento no substrato solo + esterco bovino na profundidade de $3 \mathrm{~cm}$ de plantio. Enquanto o menor desenvolvimento das plântulas ocorreu na profundidade $1,5 \mathrm{~cm}$ no substrato no solo (Tabela 7).

Resultados semelhantes foram obtidos por Sousa et al. (2007) em experimento avaliando a influência da profundidade de semeadura entre 1,5 a $4,5 \mathrm{~cm}$ na emergência de plântulas de $M$. oleifera, Esses pesquisadores verificaram que os maiores valores de IVE e altura de plantas foram encontrados na profundidade $2 \mathrm{~cm}$. Afirmaram ainda que a profundidade em torno de $3 \mathrm{~cm}$ é a ideal para a semeadura, pois haverá maior embebição na fase inicial da emergência, o que influencia na fase de indução do crescimento e no crescimento.

Os melhores resultados deste estudo na produção de mudas por sementes de moringa estão em consonância com os de Camargo (2011), o qual observou incremento no desenvolvimento da altura de mudas de moringa quando adicionados insumos orgânicos ao substrato de crescimento. Fato também observado por Pereira et al. (2012), que constataram aumento na altura de plantas de algodão quando adicionado diferentes doses de esterco bovino.

Tabela 7. Índice da velocidade de emergência (IVE), altura da planta, número de folhas e diâmetro do caule em mudas de moringa por sementes.

\begin{tabular}{|c|c|c|}
\hline \multirow{3}{*}{ Substrato } & \multicolumn{2}{|c|}{ Profundidade semeadura } \\
\hline & $1,5 \mathrm{~cm}$ & $3,0 \mathrm{~cm}$ \\
\hline & \multicolumn{2}{|l|}{ IVE } \\
\hline Solo + E* & $1,0527 \mathrm{aA} * *$ & $1,0804 \mathrm{aA}$ \\
\hline Solo + B & $1,0405 \mathrm{aB}$ & $1,0858 \mathrm{aA}$ \\
\hline Solo & $0,9883 \mathrm{bB}$ & $1,0498 \mathrm{aA}$ \\
\hline Regressão Polinomial & \multicolumn{2}{|l|}{ IVE } \\
\hline 1 grau & \multicolumn{2}{|c|}{$y=-0.9584+0.6756 x$} \\
\hline \multirow[t]{2}{*}{2 grau } & $\mathrm{y}=-0.9584+$ & $\mathrm{R}^{2}=99,97 \%$ \\
\hline & \multicolumn{2}{|c|}{ Altura de planta $(\mathrm{cm})$} \\
\hline Solo + E & $23,3750 \mathrm{aB}$ & 27,1417 aA \\
\hline Solo + B & $22,0492 \mathrm{aA}$ & $21,8750 \mathrm{bA}$ \\
\hline \multirow[t]{2}{*}{ Solo } & $12,7167 \mathrm{bB}$ & $19,792 \mathrm{bA}$ \\
\hline & \multicolumn{2}{|c|}{ Número de folhas } \\
\hline Solo + E & $5,3417 \mathrm{aB}$ & $7,0750 \mathrm{aA}$ \\
\hline Solo + B & $5,5833 \mathrm{aA}$ & $6,5083 \mathrm{abA}$ \\
\hline \multirow[t]{2}{*}{ Solo } & $3,8833 \mathrm{bB}$ & $5,9083 \mathrm{bA}$ \\
\hline & \multicolumn{2}{|c|}{ Diâmetro do caule } \\
\hline Solo + E & $0,1884 \mathrm{aB}$ & $0,2600 \mathrm{aA}$ \\
\hline Solo + B & $0,1425 \mathrm{bB}$ & $0,1963 \mathrm{bA}$ \\
\hline Solo & $0,0838 \mathrm{cB}$ & $0,1713 \mathrm{bA}$ \\
\hline
\end{tabular}

*E: esterco bovino; B: bagana de carnaúba; **As médias seguidas pela mesma letra não diferem estatisticamente entre si na coluna com a letra minúscula e na linha letra maiúscula, pelo Teste de Tukey ao nível de $5 \%$ de probabilidade. 
O menor valor das variáveis IVE, altura da planta, número de folhas, diâmetro do caule e número de brotações foram encontrados no substrato solo, tanto na produção de mudas por sementes de leucena e moringa, quanto na produção de mudas por estacas de leucena e gliricídia, pois neste substrato há pouca quantidade de matéria orgânica e nessas condições a água infiltra rapidamente, reduzindo a umidade do substrato e consequentemente, protelando assim, o processo de germinação e emergência de plântulas. Além da menor quantidade de nutrientes como potássio, nitrogênio e fosforo no substrato solo.

Em sementes de moringa, Silva et al. (2004), relataram que 30 dias após a semeadura, encontraram os maiores valores das variáveis altura de planta, número de folhas e diâmetro do caule, na profundidade de $3 \mathrm{~cm}$, concordando com os achados deste estudo.Por outro lado, também foi importante a qualidade das sementes de moringa que foram selecionadas para o experimento, as quais propiciaram uma emergência mais rápida e uniforme produzindo plântulas com maiores dimensões e características semelhantes aos achados de Minuzzi et al. (2010).

A matéria orgânica incluída nos substratos para a produção de mudas,é importante pela colaboração na retenção de água em quantidade adequada, o que favorece a emergência das plântulas (ARAÚJO ; SOBRINHO, 2011).

\section{CONCLUSÕES}

A produção de mudas de leucena e moringa por sementes é viável em substratos adicionados de matéria orgânica tanto de origem animal quanto vegetal, na profundidade de até $3 \mathrm{~cm}$.

Para produzir mudas de leucena e gliricídia por estacas, o tamanho de $40 \mathrm{~cm}$ em substratos adicionados de material orgânico de origem vegetal ou animal é eficaz.

\section{REFERÊNCIAS}

ANDRADE, B. M. S.; SOUZA, S. F.; SANTOS, C. M. C.; MEDEIROS, S. S.; MOTA, P. S. S.; CURADO, F. F. Uso da gliricídia (Gliricidia sepium) para alimentação animal em Sistemas Agropecuários Sustentáveis. Scientia Plena, Aracaju, v. 4, n. 4, p. 1-7, 2015.

ARAÚJO, A. P.; SOBRINHO, S. P. Germinação e produção de mudas de tamboril (Enterolobium Contortisiliquum (Vell.) Morong) em diferentes substratos. Revista Árvore, Viçosa, v. 35, n. 3, supl. 1, 2011.

ARAÚJO, J. R.; SANTOS, L. D.; SILVA, L. C. R.; SANTOS, O. O.; MEURER, F. Digestibilidade aparente de ingredientes do Semi-Árido Nordestino para tilápia do
Nilo. Ciência Rural, Santa Maria, v. 42, n. 5, p. 900-903, 2012.

ARAÚJO, E. F.; AGUIAR, A. S.; ARAUCO, A. M. S.; GONÇALVES, E. O.; ALMEIDA, K. N. S. Crescimento e qualidade de mudas de paricá produzidas em substratos à base de resíduos orgânicos. Nativa, Sinop, v. 5, n. 1, p. 16-23, 2017.

ARRUDA, A. M. V.; MELO, A. S.; OLIVEIRA, V. R. M.; SOUZA, D. H.; DANTAS, F. D. T.; OLIVEIRA, J. F. Avaliação nutricional do feno de leucena com aves caipiras. Acta Veterinaria Brasilica, Porto Alegre, v. 4, n. 3, p. 162-167, 2010.

BAYÃO, G. F. V.; EDVAN, R. L.; CARNEIRO, M. S. S.; FREITAS, N. E.; PEREIRA, E. S.; PACHECO, W. F.; BEZERRA, L. R.; ARAÚJO, M. J. Desidratação e composição química do feno de Leucena (Leucena leucocephala) e Gliricidia (Gliricidia sepium). Revista Brasileira de Saúde Produção Animal, Salvador, v. 17, n. 3, p. 365-373, 2016.

CADEAU, F. Uso da torta de semente de moringa (Moringa oleifera Lam) na alimentação de frangos de corte. 2017. 56p. Dissertação (Mestrado em Nutrição Animal). Universidade Federal Rural de Pernambuco, Recife, 2017.

CÂMARA, C. S.; ALVES, A. A.; MOREIRA FILHO, M. A.; GARCEZ, B. S.; AZEVÊDO, D. M. M. R. Dietas contendo fenos de leucena ou estilosantes para cabras Anglo-Nubianas de tipo misto em lactação. Revista Ciência Agronômica, Fortaleza, v. 46, n. 2, p. 443-450, 2015.

CAMARGO, R. Substratos para produção de mudas de Moringa oleífera L. em bandejas. Revista Agropecuária Técnica, Areia, v. 32, n. 1, p. 72-78, 2011.

CAVAlCANTE, A. C. P.; SILVA, A. G.; SILVA, M. J. R.; ARAÚJO, R. C. Produção de mudas de Gliricídia com diferentes substratos orgânicos. Revista Agrarian, Dourados, v. 9, n. 33, p. 233-240, 2016.

EVAngelistA, A. R.; LIMA, J. A. Produção de feno. Informe Agropecuário, Belo Horizonte, v. 34, n. 277, p. 43-52, 2013.

IPECE - Instituto de Pesquisa e Estratégia Econômica do Ceará, Perfil municipal 2017, ano I. Disponível em:http://www.ipece.ce.gov.br/perfil_basico_municipal/2 017/Redencao.pdf Acesso em 30/05/2018

KIILL, L. H. P.; MARTINS, C. T. V.; LIMA, P. C. F. Moringa oleifera: registro dos visitantes florais $\mathrm{e}$ potencial apícola para a região de Petrolina, PE. Petrolina: Embrapa Semiárido, Boletim de Pesquisa e Desenvolvimento, 2012. 19 p.

KORNDORFER, G. H. Adubação orgânica. Uberlândia: Campus Umuarama. 2003 Disponivel em: 
http://www.dpv24.iciag.ufu.br/new/dpv24/Apostilas/Apos tila\%20Ad.\%20Organicos\%2003.pdf Acesso em: 08 de junho de 2018.

LOPES, I. R. V.; FREITAS, E. R.; NASCIMENTO, G. A. J.; VIANA NETO, J. L.; CRUZ, C. E. B.; BRAZ, N. M. Inclusão de fenos de folha de leucena e de cunhã na ração de poedeiras. Archivos de Zootecnia, Cordoba, v. 63, n. 241, p. 183-190, 2014.

MARCHESE, J. A.; PISSAIA, E.; BOCCHESE, V. C. C.; CAMBRUZZI, E.; COLUSSI, G.; HART, V.; MAGIERO, E. C. Estacas de diferentes diâmetros na propagação de Lippia alba (Mill.) N.E.Br. - Verbenaceae, Revista Brasileira de Plantas Medicinais, Botucatu, v. 12, p. 506-509, 2010.

MARIN, A. M. P.; MENEZES, R. S. C.; SALCEDO, I. H. Produtividade de milho solteiro ou em aléias de Gliricídia adubado com duas fontes orgânicas. Pesquisa Agropecuária Brasileira, Brasília, v. 42, n. 5, p. 669677, 2007.

MARINHO, J. B. M.; ARRUDA, A. M. V.; FERNANDES, R. T. V.; MELO, A. S.; SOUZA, R. F.; SANTOS, L. O. G.; FIGUEIRÊDO, L. C.; FERNANDES, R. T. V.; MESQUITA, A. C. N. Uso da moringa na alimentação animal e humana: Revisão. PUBVET, Londrina, v. 10, n. 8, p. 619-627, 2016.

MAYER, J. L. S.; BIASI, L. A.; BONA, C. Capacidade de enraizamento de estacas de quatro cultivares de Vitis L. (Vitaceae) relacionada com os aspectos anatômicos. Acta Botanica Brasilica, Belo Horizonte, v. 20, n. 3, p. 563-8, 2006.

MOYO, B.; MASIKA, P. J.; HUGO, A.; MUCHENJE, V. Nutritional characterization of moringa (Moringa oleifera Lam.) leaves. African Journal of Biotechnology, v. 10, p. 12925-12933, 2013.

MINUZZI, A.; BRACCINI, A. L.; RANGEL, M. A. S.; SCAPIM, C. A.; BARBOSA, M. C.; ALBRECHT, L. P. Qualidade de sementes de quatro cultivares de soja, colhidas em dois locais no estado de Mato Grosso do Sul. Revista Brasileira de Sementes, Londrina, v. 32, n. 1, p. 176-185, 2010.

NKUKWANA, T. T.; MUCHENJE, V.; MASIKA, P. J.; MUSHONGA, B. Intestinal morphology, digestive organ size and digesta $\mathrm{pH}$ of broiler chickens fed diets supplemented with or without Moringa oleifera leaf meal. South African Journal of Animal Science, Pretoria, v. 45 , n. 4, p. 362-370, 2015.

OLIVEIRA, A. B.; FILHO, S. M.; BEZERRA, A. M. B.; BRUNO, R. L. A. Emergência de plântulas de copernicia hospita martius em função do tamanho da semente, do substrato e ambiente. Revista Brasileira de Sementes, Londrina, v. 31, n. 1, p. 281-287, 2009.
OLIVEIRA, M. V. M.; CHIODI, M. S.; FERNANDES, H. J.; LISITA, F. O.; LUZ, D. F.; SALLA, L. E. Moringa oleifera na alimentação de bezerros lactentes da raça Pantaneira. Revista Brasileira de Saúde e Produção Animal, Salvador, v. 18, n. 1, p. 152-160, 2017.

PEREIRA JÚNIOR, L. R.; GAMA, J. S. N.; RESENDE, I. R. A. Propagação vegetativa de Gliricidia sepium no Curimataú paraibano. Revista Verde de Agroecologia e Desenvolvimento Sustentável, Mossoró, v. 3, n. 3, p. 17 $-20,2008$.

PEREIRA, J. R.; ARAÚJO, W. P.; FERREIRA, M. M. M.; LIMA, F. V.; ARAÚJO, V. L.; SILVA, M. N. B. Doses de esterco bovino nas características agronômicas e de fibras do algodoeiro herbáceo BRS Rubi. Revista Agro@mbiente, Boa Vista, v. 6, n. 3, p. 195-204, 2012.

SÁNCHEZ, N. R.; SPÖRNDIY, E.; LEDIN, I. Effect of feeding different levels of foliage of Moringa oleifera to creole dairy cows on intake, digestibility, milk production and composition. Livestock Science, Miles City, v. 101, p. 24-31, 2006.

SANTANA NETO, J. A.; OLIVEIRA, V. S.; VALENÇA, R. L. Leguminosas adaptadas como alternativa alimentar para ovinos no semiárido - revisão. Revista de Ciências Agroveterinárias, Lages, v. 14, n. 2, p. 191-200, 2015.

SETUBAL, J. W.; NETO A. F. C. Efeito de substratos alternativos e tipos de bandeja na produção de mudas de pimentão. Horticultura Brasileira, Vitória da Conquista, v. 18, p. $593-594,2000$

SEGUNDO, L. F. F.; ARARIPE, N. M. B. A.; LOPES, J. B. Substituição do Farelo de Soja Pelo Feno de Leucena na Alimentação de Alevinos de Tilápia. Revista Científica de Produção Animal, Areia, v. 8, n. 2, p. 2834, 2006.

SILVA, D.; SOUZA, S. A. O.; LIMA, P. C. F.; KIILL, L. H. P.; ARAÚJO, J. L. P. Influência da profundidade de semeadura e emergência de plântulas de Moringa oleifera lam. (Moringaceae). XXVII Reunião Nordestina de Botânica, Petrolina, 22 a 25 de março de 2004.

SILVA, F. A. S.; AZEVEDO, C. A. V. The Assistat Software Version 7.7 and its use in the analysis of experimental data. African Journal Agricultural Research, v. 11, n. 39, p. 3733-3740, 2016.

SILVA, M. D. A.; CARNEIRO, M. S. S.; PINTO, A. P.; POMPEU, R. C. F. F.; SILVA, D. S.; COUTINHO, M. J. F.; FONTENELE, R. M. Avaliação da composição químico-bromatológica das silagens de forrageiras lenhosas do semiárido brasileiro. Semina: Ciências Agrárias, Londrina, v. 36, n. 1, p. 571-578, 2015.

SOUSA, A. H.; RIBEIRO, M. C. C.; MENDES, V. H. C.; MARACAJA, P. B.; COSTA, D. M. Profundidades e posições de semeadura na emergência e no 
desenvolvimento de plântulas de moringa. Caatinga, Mossoró, v. 20, n. 4, p. 56-60, 2007.

THOM, E. C. The discomfort index. Weatherwise, v. 12, n. 2, p. 57-59, 1959.
UFELE, A. N.; EBENEBE, C. I.; IGWE, I. I.; MOGBO, T. C.; AKUNNE, E. C.; AZIAGBA, B. O. The effects of drumstick tree (Moringa oleifera) leaf meal on the average weight gain of domestic rabbits (Oryctolagus cuniculus). The Bioscientist Journal, Awka, v.1, n.1, p.106-108, 2013. 